\title{
Humanities in medical education: between reduction and integration
}

\author{
Taehee Han
}

Department of Medical Education, Sungkyunkwan University School of Medicine, Suwon, Korea

\section{의과대학 인문학 교육: 환원과 통합 사이에서}

성균관대학교 의과대학 의학교육학교실

\section{한태희}

Reductive logic has been a major reasoning style in development of modern biomedical sciences. However, when "medical humanities" is developed by reductive reasoning, integrative and holistic values of humanities tend to be weakened. In that sense, identity and significance of "medical humanities" continue to be controversial despite of its literal clarity. Humanities in medical education should be established by strengthening humanistic and socialistic aspects of regular medical curriculum as well as developing individual "medical humanities" programs.

Key Words: Humanities, Integration, Medicine, Reduction

\section{의학, 인문학, "의료인문학"}

현대 세계의 주류 의학(medicine)은 그리스· 로마 의학에 뿌리를 두고 중세 아랍의학과 근대 서양과학이 계승 발전시 킨 복합적 학문 체계이다. 이러한 의학의 성격을 과학적 관점 또는 인문학 내지 예술의 관점에서 규정하는 일은 시대에 따 라 여전히 진행 중인 사안이다[1,2]. 의학을 포함한 서양 학문 체계에서 과학(sciences)과 인문학(humanities)은 두 중심축 이며 이러한 관점에서 인문학은 의학의 주요 속성이라 할 수 있다[1,2]. 최근 200년 가까이 진행된 의생명과학(biome- dical science)의 발전은 질병의 이해와 치료 측면에서 눈부 신 향상에 기여했지만, 의학 및 의학교육에서 인문학의 위축 을 초래하였다. 이는 현대 사회의 변화와 더불어 의사와 의료 문화의 비인간화에 기여했다는 비판과 동시에 의학교육에서 인문학 강화의 주된 근거가 되고 있다[2,3,4].

인문학은 인류 문화를 연구하는 복합적 학문 분야이며, 역 사학, 문학, 철학, 고전학, 예술 등을 포함한다. 이렇게 인류의 총체적 경험을 비평적, 추론적으로 다루는 점이 자아와 환경 에 대한 통찰과 이해에 기여한다는 주된 근거이다. 국내외 많 은 의과대학들이 교육목표로 내세우는 유능한 의사, 의과학 자로서의 전문성(professionalism)이나 의료 분야 리더십의
Received: June 24, 2015 • Revised: June 30, 2015 • Accepted: June 30, 2015 Corresponding Author: Taehee Han (http://orcid.org/0000-0002-7247-3283)

Department of Medical Education, Sunkyunkwan University School of Medicine, 2066 Seobu-ro, Jangan-gu, Suwon 440-746, Korea

Tel: +82.31.299.6220 Fax: +82.31.299.6239 email: thhan5@skku.edu
Korean J Med Educ 2015 Sep; 27(3): 163-165. http://dx.doi.org/10.3946/kjme.2015.27.3.163 eISSN: 2005-7288

(C) The Korean Society of Medical Education. All rights reserved. This is an open-access article distributed under the terms of the Creative Commons Attribution Non-Commercial License (http:// creativecommons.org/licenses/by-nc/3.0/), which permits unrestricted non-commercial use, distribution, and reproduction in any medium, provided the original work is properly cited. 
근본이 결국 깊은 의학적 지식에 더하여 환자, 집단, 사회에 대한 통찰과 이해라는 점에서 의과대학 인문학 교육의 당위 성이 주장되고 있다[2,3,4].

“의료인문학(medical humanities)"은 의학적 지식의 적용 및 그 영역에서 인문학적 통찰 및 연구를 수행하는 학문 및 교육 단위로서 주장되고 있으며, 의학사, 의철학, 의료윤리 등 이 주 분야이다[2,3]. 그러나 의학 및 인문학 각각이 이미 복 합적 학문체계이며 고유의 접근 방식을 가지고 있어서, 현대 의학과 의학교육의 주된 바탕을 이루는 환원주의적 사고방식 으로 접근하는 순간 인문학의 통합적이고 총체적 의미는 위 축될 수밖에 없는 것이다[4,5]. 이러한 의미에서 "의료인문학" 이라는 단어가 주는 명료함에 비해 그 구체적 의미 및 정체성 에 있어서는 여전히 논란이 이어지고 있다[4,5]. 또한 기존 의 과대학 교육 및 수련 과정에서 진료 및 환자와의 관계 등을 다뤄온 “의술(art of medicine)”의 영역과 이를 넘어 집단적, 사회적 이슈를 다뤄온 사회의학(social medicine)과의 관계 가 불분명하여 이러한 논란들은 의학교육에의 적용에까지 이 어지고 있다.

\section{의과대학 인문학 교육}

의과대학 교육에서 인문학 강화의 추진을 위해 이미 포화 된 교과과정에 얼마나 “의료인문학” 과목을 신설할 지는 논의 가 필요하다. 언급된 바와 같이 인문학이 이미 의학의 중요한 한 부분이라면[1,2], 의과대학 교육의 인문학 강화는 기존의 교과과정 범위 내에서 우선 시도될 수 있기 때문이다. 효과적 인문학 교육을 위해서는 별도의 구체적 내용을 다루는 과목 의 신설보다는 기존 과목에 인문사회적 관점을 강화하여 총 체적 시각과 통찰을 지향하는 것이 바람직할 수 있다. 임상 증 례에 관련된 각종 인문 사회적인 이슈들은 소그룹 토의나 임 상 실습에서 다양한 형태로 제시 및 논의될 수 있으며 $[6,7]$, 기초의학 및 생명과학의 많은 내용들이 과학사 및 철학의 관 점에서 논의될 수 있다[7,8]. 또한 추가적 “의료인문학" 과목 을 개설하여 의학사, 의료윤리 등 특정 이슈들에 대하여 좀더 깊이 있는 성찰도 가능할 것이다. 즉, 기존의 의학교육 틀에서 의 통합적 접근과 추가적 프로그램의 적절한 운용이 필요하
다. 학부 의학교육의 범위를 넘어 좀더 전문적 연구들은 "의료 인문학" 교수 및 대학원 교육의 영역이 될 수 있을 것이다. 의과대학 인문학 교육이 지향하고 있는 공감, 소통, 인성, 전문성 등의 덕목들을 어떻게 평가하는가는 매우 도전적이고 현실적인 문제이다. 평가의 통계적 신뢰성이 강조되는 현실 에서 "객관식" 평가 방법이 선호되고 발전되어 왔지만, 인문학 영역에서 발표와 쓰기는 여전히 중요한 평가 방식이다. 쓰기 평가의 객관성을 향상시키기 위해 시나리오와 연결된 단답형 쓰기 평가라든가 발표 및 포트폴리오 작성과 병행하여 평가 하는 시도가 보고되었으며, 인성이나 전문성 같이 좀더 복합 적인 덕목의 평가를 위해서 인성이나 전문성의 구성 요소들 을 종합적으로 또한 시간적 경과 속에서 평가하려는 시도들 이 보고되었다[9].

"의료인문학"의 정체성 및 목표에 대한 논란은 여전히 진행 중이지만, 근래 들어 의학교육에서 인문학을 강화한 노력들 이 의과대학 졸업생들의 인성과 전문성 등을 향상시켰다는 보고들이 있다[2,3,7,9]. 이러한 성공을 위해서는 의학 및 의 학교육에서 인문학이 차지하는 의미를 문화적인 바탕에서 통 찰하고, 그 가치와 목표를 공유하는 교수 요원의 폭을 넓히는 것 또한 중요한 과제라 할 수 있다.

Acknowledgements: None.

Funding: None.

Conflicts of interest: None.

\section{REFERENCES}

1. Kang S. Two cultures in medicine: reduction or construction? Korean J Med Hist 2002; 11: 1-19.

2. Baum M. Teaching the humanities to medical students. Clin Med 2002; 2: 246-249.

3. Meng $\mathrm{KH}$. Teaching medical humanities in Korean medical schools: tasks and prospect. Korean J Med Educ 2007; 19: 5-11.

4. Friedman LD. The precarious position of the medical 
humanities in the medical school curriculum. Acad Med 2002; 77: 320-322.

5. Coulehan J. What is medical humanities and why? [Internet]. New York University School of Medicine; 2008 [cited 2008 January 25]. Available from: http://medhum.med.nyu.edu/blog/?p=100.

6. Harper AC. A proposal to incorporate a public health perspective into clinical teaching. Clin Teach 2011; 8: 114-117.

7. Eichbaum QG. Thinking about thinking and emotion: the metacognitive approach to the medical humanities that integrates the humanities with the basic and clinical sciences. Perm J 2014; 18: 64-75.

8. Brawer JR. The value of a philosophical perspective in teaching the basic medical sciences. Med Teach 2006; 28: $472-474$.

9. Peters AS, Greenberger-Rosovsky R, Crowder C, Block SD, Moore GT. Long-term outcomes of the New Pathway Program at Harvard Medical School: a randomized controlled trial. Acad Med 2000; 75: 470-479. 